\title{
PENENTUAN PENAMBAHAN VOLUME AIR KONSTAN PADA PENGOMPOSAN SAMPAH DAUN MENGGUNAKAN PENDEKATAN GRAFIS RESERVOIR
}

\section{Ganjar Samudro; Sri Sumiyati; Dian Asri Puspa Ratna; Sindi Martina Hastuti dan Vaneza Citra Kurnia}

Departemen Teknik Lingkungan, Fakultas Teknik, Universitas Diponegoro, Jl. Prof. H. Soedarto, SH, Tembalang, Semarang

Email: ganjarsamudro@gmail.com

\begin{abstract}
Abstrak
Penentuan penambahan volume air konstan pada pengomposan sampah daun dilakukan untuk mendapatkan volume air optimum selama 1 siklus. Penambahan secara manual pada proses pengomposan dapat menyebabkan hambatan proses dekomposisi materi, ketidakpraktisan operasional, dan perubahan parameter kualitas kompos. Tujuan penentuan ini adalah untuk mendapatkan penambahan volume air konstan dalam proses pengomposan sampah daun secara kontinyu hingga mencapai persentase kadar air yang diinginkan. Metode grafis reservoir diterapkan dengan urutan tabulasi hasil dalam satuan persentase kadar air ekuivalen dengan volume air yang ditambahkan dan digambarkan dalam bentuk grafis akumulasi persentase kadar air. Hasil yang didapatkan adalah penambahan volume air konstan dengan kadar air yang diinginkan 50\% sebesar $334 \mathrm{ml} / \mathrm{kg}$ sampah/siklus $\approx 100 \mathrm{ml} / \mathrm{l} \mathrm{sampah/siklus} \approx 24 \%$ penambahan volume air $\approx 17 \mathrm{ml} /$ hari debit input. Sedangkan penambahan volume air konstan dengan kadar air yang diinginkan $60 \%$ sebesar $717 \mathrm{ml} / \mathrm{kg}$ sampah/siklus $\approx 215 \mathrm{ml} / \mathrm{l} \mathrm{sampah} / \mathrm{siklus} \approx 16 \%$ penambahan volume air $\approx 36 \mathrm{ml} / \mathrm{hari}$ debit input. Semakin besar kadar air yang diinginkan, maka semakin besar penambahan volume air konstan dan debit input, serta semakin kecilnya persentase penambahan volume air yang mengindikasikan kapasitas tampung reservoir yang semakin kecil.
\end{abstract}

Kata kunci: volume air konstan, pengomposan, sampah daun, grafis reservoir

\begin{abstract}
Determination of the increase of the constant water volume in leaves litter composting is conducted to obtain the optimum water volume in 1 cycle. The manual addition on composting process may inhibit the decomposition of the substances, cause the unpractical operation, and change the compost quality parameters. The aim of this determination is to obtain the increase of constant water volume on a continuous composting process of leaves litter until reaching desired the percentage of water content. Reservoir graphical method is applied by the sequence result table in water content percentage unit equivalent with the increase of water volume; and is described in the form of water content percentage accumulation. The results obtained were $334 \mathrm{ml} / \mathrm{kg}$ leaf litter/cycle $\approx 100 \mathrm{ml} / \mathrm{l}$ leaf litter/cycle $\approx 24 \%$ of the increase of water volume $\approx 17 \mathrm{ml} /$ days input flow rate for the increase of constant water volume by water content of $50 \%$. Other results obtained were $717 \mathrm{ml} / \mathrm{kg}$ leaf litter/cycle $\approx 215 \mathrm{ml} / \mathrm{l}$ leaf litter/cycle $\approx 16 \%$ of the increase of water volume $\approx 36 \mathrm{ml} /$ days input flow rate for the increase of constant water volume by water content of $60 \%$. The higher the desired water content, the higher the increase of constant water volume and the input flow rate. The lower the increase of water volume percentage indicates the lower reservoir capacity.
\end{abstract}

Keywords: constant water volume, composting, leaf litter, reservoir graphic 


\section{PENDAHULUAN}

Pengomposan sampah daun secara manual menimbulkan banyak permasalahan operasional yang berakibat pada hasil pengomposan, salah satunya adalah penambahan volume air secara tidak kontinyu. Hambatan proses dekomposisi materi dan perubahan parameter kualitas kompos merupakan beberapa hal penyebab perubahan hasil pengomposan dari ketidakteraturan penambahan volume air. Volume air yang cukup mengindikasikan kadar air yang cukup, selanjutnya proses pengomposan dapat berjalan dengan optimal. Salah satu permasalahan kadar air kompos adalah berkurangnya kadar air tumpukan kompos selama proses pengomposan, oleh karena itu perlu dilakukan penambahan air dan pengadukan (Suehara dkk, 1999). Menurut Chang dkk (2007), kadar air mempunyai peran yang kritis dalam rekayasa pengomposan karena dekomposisi material organik bergantung pada ketersediaan kandungan air. Sedangkan menurut Som dkk (2009), salah satu faktor kunci yang menunjukkan pengomposan berjalan dengan cepat adalah kadar air. Kadar air mempengaruhi laju dekomposisi dan suhu karena mikroorganisme membutuhkan kadar air yang optimal untuk menguraikan material organik (Dian dkk, 2017). Oleh karena itu, penyelesaian teknis operasional perlu dilakukan untuk mendapatkan volume air yang ditambahkan pada proses pengomposan secara kontinyu.

Pendekatan grafis reservoir banyak digunakan untuk menentukan kapasitas tampung reservoir dalam penyediaan air minum dan jumlah tumbuhan dalam penghijauan perkotaan. Perhitungan volume efektif reserovir secara grafis dilakukan dengan membuat suatu grafik mengenai fluktuasi kebutuhan air, yang menggambarkan kebutuhan air selama kurun waktu 24 jam (Sianturi, 2013). Metode Grafis (Ripple Methode) dengan memplot kumulatif besarnya inflow dan outflow, dimana selisih terbesar, antara kedua kurva tersebut merupakan kapasitas yang dibutuhkan (Bagiawan, 2013). Unit tampung karbondioksida yang kurang lebih merupakan luas area ruang terbuka hijau, ditentukan menggunakan metode penentuan unit tampung air (Samudro dan Mangkoedihardjo, 2006). Pendekatan grafis reservoir ini memberikan informasi besar volume air, persentase penambahan volume air, dan debit input dalam 1 siklus pengomposan.

Tujuan penentuan ini adalah untuk mendapatkan penambahan volume air konstan dalam proses pengomposan sampah daun secara kontinyu hingga mencapai persentase kadar air yang diinginkan.

\section{METODE PENELITIAN}

Metode penelitian merupakan metode kuantitatif deskriptif. Langkah-langkah metode ini diketengahkan sebagai berikut: 
1. Penelitian penambahan volume air pada proses pengomposan selama 30 hari. Kadar air selama proses pengomposan diamati dan dicatat, kemudian penambahan air dilakukan pada saat kadar air yang diinginkan dibawah $50 \%$ dan $60 \%$.

Pemilihan kadar air yang diinginkan 50\% dan 60\% berdasarkan pada kadar air optimum dalam proses pengomposan sampah daun dengan ukuran bahan $1 \mathrm{~cm}$ (Dian dkk, 2017; Sindi dkk, 2017; Vaneza dkk, 2017).

2. Kalkulasi penambahan air dan akumulasi dengan kadar air yang diinginkan $50 \%$ dan $60 \%$. Identifikasi ini dibuat dalam bentuk tabulasi yang terdiri dari kadar air dan penambahan airnya, kemudian dilakukan koreksi penambahan air dan akumulasinya.

Penambahan air mengacu pada formula Ministry of Agriculture and Food (1998), yaitu:

$$
\mathrm{a}=\frac{M b-M}{M-M a}
$$

dimana:

a : Jumlah air yang dibutuhkan (liter)

M : Kandungan kadar air yang diinginkan (\%)

Ma : Kandungan kadar air dari air (100\%)

$\mathrm{Mb} \quad$ : Kandungan kadar air dari bahan kompos (\%)

Koreksi penambahan air mengikuti formula dimana tanda (-) merupakan indikator kelebihan kadar air dan ditetapkan menjadi nilai $0 \mathrm{~mL}$ atau tidak ada penambahan air. Sedangkan tanda (+) merupakan indikator kekurangan air dan ditetapkan sama dengan nilai penambahan air.

$$
\text { Penambahan air }(\%)=\frac{\text { Koreksi Penambahan Air }}{\text { Jumlah Koreksi Penambahan Air }} \times 100 \%
$$

$$
\text { Akumulasi penambahan air (\%)=Penambahan Air hari ke }-0+\text { Penambahan Air hari ke }-1
$$

3. Kalkulasi penambahan volume air, prosentase penambah+an volume air, dan debit input. $\Delta$ Volume air $=$ Akum. $\Delta$ Volume Air Tertinggi - Akum. $\Delta$ Volume Air Terendah (1.4) dimana:

$\Delta$ : Penambahan

$$
\text { Qin = Vol.Koreksi Penambahan Air/t Pengomposan }
$$

dimana:

Qin : Debit input

Vol. Koreksi Penambahan Air : Volume Koreksi Penambahan Air

t Pengomposan : Waktu pengomposan 


\section{HASIL DAN PEMBAHASAN}

Hasil pengamatan kadar air yang diinginkan 50\% bervariasi antara $44-55 \%$ dengan selisih ratarata sebesar $0,5 \%$, sedangkan kadar air yang diinginkan $60 \%$ bervariasi antara 55 - 66\% dengan selisih rata-rata sebesar $0,5 \%$. Selisih rata-rata sebesar $0,5 \%$ mengindikasikan bahwa penambahan air memiliki bias/error kecil sebesar $1 \%$ untuk penambahan air secara manual. Berikut ini diketengahkan Tabel 1 mengenai kalkulasi penambahan air dengan perhitungan mengacu pada formula (1); (2); (3); (4); dan (5).

Tabel 1. Kalkulasi Penambahan Air

\begin{tabular}{|c|c|c|c|c|c|c|c|c|c|c|}
\hline \multirow[t]{2}{*}{ Hari } & \multicolumn{2}{|c|}{ Kadar Air (\%) } & \multicolumn{2}{|c|}{$\begin{array}{l}\text { Penambahan Air } \\
\text { (ml) }\end{array}$} & \multicolumn{2}{|c|}{$\begin{array}{c}\text { Koreksi } \\
\text { Penambahan } \\
\text { Air (ml) }\end{array}$} & \multicolumn{2}{|c|}{$\begin{array}{c}\text { Penambahan Air } \\
(\%)\end{array}$} & \multicolumn{2}{|c|}{$\begin{array}{c}\text { Akumulasi } \\
\text { Penambahan Air } \\
(\%)\end{array}$} \\
\hline & $50 \%{ }^{1}$ & $60 \% 1$ & $\mathbf{5 0 \%}$ & $60 \%$ & $\mathbf{5 0 \%}$ & $60 \%$ & $50 \%$ & $60 \%$ & $50 \%$ & $60 \%$ \\
\hline 1 & 55 & 66 & -100 & $-150^{2}$ & 0 & $0^{3}$ & 0 & $0^{4}$ & 0 & 0 \\
\hline 2 & 50 & 64 & 0 & -100 & 0 & 0 & 0 & 0 & 0 & $0^{5}$ \\
\hline 3 & 49 & 61 & 20 & -25 & 20 & 0 & 4 & 0 & 4 & 0 \\
\hline 4 & 47 & 57 & 60 & 75 & 60 & 75 & 12 & 7 & 16 & 7 \\
\hline 5 & 48 & 55 & 40 & 125 & 40 & 125 & 8 & 12 & 24 & 19 \\
\hline 6 & 53 & 57 & -60 & 75 & 0 & 75 & 0 & 7 & 24 & 26 \\
\hline 7 & 56 & 62 & -120 & -50 & 0 & 0 & 0 & 0 & 24 & 26 \\
\hline 8 & 54 & 58 & -80 & 50 & 0 & 50 & 0 & 5 & 24 & 30 \\
\hline 9 & 56 & 62 & -120 & -50 & 0 & 0 & 0 & 0 & 24 & 30 \\
\hline 10 & 54 & 58 & -80 & 50 & 0 & 50 & 0 & 5 & 24 & 35 \\
\hline 11 & 50 & 57 & 0 & 75 & 0 & 75 & 0 & 7 & 24 & 42 \\
\hline 12 & 49 & 63 & 20 & -75 & 20 & 0 & 4 & 0 & 28 & 42 \\
\hline 13 & 46 & 62 & 80 & -50 & 80 & 0 & 16 & 0 & 44 & 42 \\
\hline 14 & 44 & 61 & 120 & -25 & 120 & 0 & 24 & 0 & 68 & 42 \\
\hline 15 & 52 & 59 & -40 & 25 & 0 & 25 & 0 & 2 & 68 & 44 \\
\hline 16 & 53 & 56 & -60 & 100 & 0 & 100 & 0 & 9 & 68 & 53 \\
\hline 17 & 54 & 59 & -80 & 25 & 0 & 25 & 0 & 2 & 68 & 56 \\
\hline 18 & 52 & 59 & -40 & 25 & 0 & 25 & 0 & 2 & 68 & 58 \\
\hline 19 & 50 & 58 & 0 & 50 & 0 & 50 & 0 & 5 & 68 & 63 \\
\hline
\end{tabular}




\begin{tabular}{|c|c|c|c|c|c|c|c|c|c|c|}
\hline \multirow[t]{2}{*}{ Hari } & \multicolumn{2}{|c|}{ Kadar Air (\%) } & \multicolumn{2}{|c|}{$\begin{array}{c}\text { Penambahan Air } \\
\text { (ml) }\end{array}$} & \multicolumn{2}{|c|}{$\begin{array}{c}\text { Koreksi } \\
\text { Penambahan } \\
\text { Air (ml) }\end{array}$} & \multicolumn{2}{|c|}{$\begin{array}{c}\text { Penambahan Air } \\
\text { (\%) }\end{array}$} & \multicolumn{2}{|c|}{$\begin{array}{c}\text { Akumulasi } \\
\text { Penambahan Air } \\
\text { (\%) }\end{array}$} \\
\hline & $50 \%{ }^{1}$ & $60 \%{ }^{1}$ & $50 \%$ & $60 \%$ & $50 \%$ & $60 \%$ & $50 \%$ & $60 \%$ & $50 \%$ & $60 \%$ \\
\hline 20 & 54 & 57 & -80 & 75 & 0 & 75 & 0 & 7 & 68 & 70 \\
\hline 21 & 53 & 58 & -60 & 50 & 0 & 50 & 0 & 5 & 68 & 74 \\
\hline 22 & 52 & 57 & -40 & 75 & 0 & 75 & 0 & 7 & 68 & 81 \\
\hline 23 & 50 & 61 & 0 & -25 & 0 & 0 & 0 & 0 & 68 & 81 \\
\hline 24 & 58 & 49 & 20 & 50 & 20 & 50 & 96 & 5 & 72 & 86 \\
\hline 25 & 56 & 48 & 40 & 100 & 40 & 100 & 8 & 9 & 80 & 95 \\
\hline 26 & 62 & 46 & 80 & -50 & 80 & 0 & 16 & 0 & 96 & 95 \\
\hline 27 & 61 & 50 & 0 & -25 & 0 & 0 & 0 & 0 & 96 & 95 \\
\hline 28 & 60 & 54 & -80 & 0 & 0 & 0 & 0 & 0 & 96 & 95 \\
\hline 29 & 58 & 55 & -100 & 50 & 0 & 50 & 0 & 5 & 96 & 100 \\
\hline \multirow[t]{2}{*}{30} & 63 & 49 & 20 & -75 & 20 & 0 & 4 & 0 & 100 & 100 \\
\hline & & & & Jumlah & $500^{6}$ & 1.075 & 100 & 100 & & \\
\hline
\end{tabular}

Catatan:
a. \%kadar air pengomposan yang diinginkan
b. kadar air berlebih $>$ \%kadar air pengomposan yang diinginkan
C. (-) pada (**) menjadi 0
d. Penambahan air $(\%)=(0 / 1.075) \times 100 \%=0 \%$
e. Akumulasi penambahan air $=$ Penambahan air $1(\%)+$ Penambahan air $1(\%)=0 \%+0 \%=0 \%$, dan seterusnya
f. Jumlah koreksi penambahan air = total penambahan volume air

Berdasarkan hasil kalkulasi Tabel 1, maka diplotkan pada Gambar 1 dan Gambar 2 untuk mendapatkan ekuivalen \% akumulasi penambahan air. 


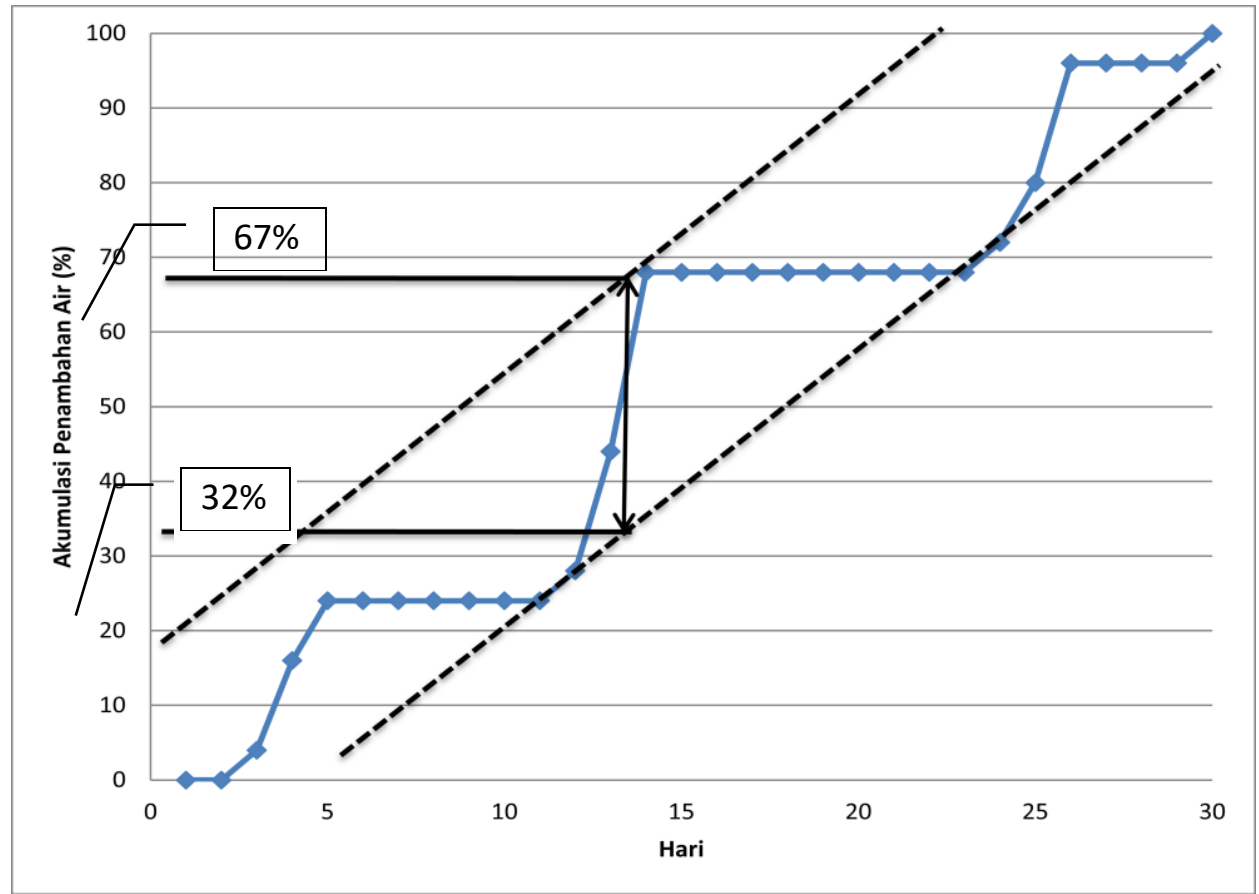

Gambar 1. Persentase Penambahan Air pada Kadar Air Pengomposan 50\%

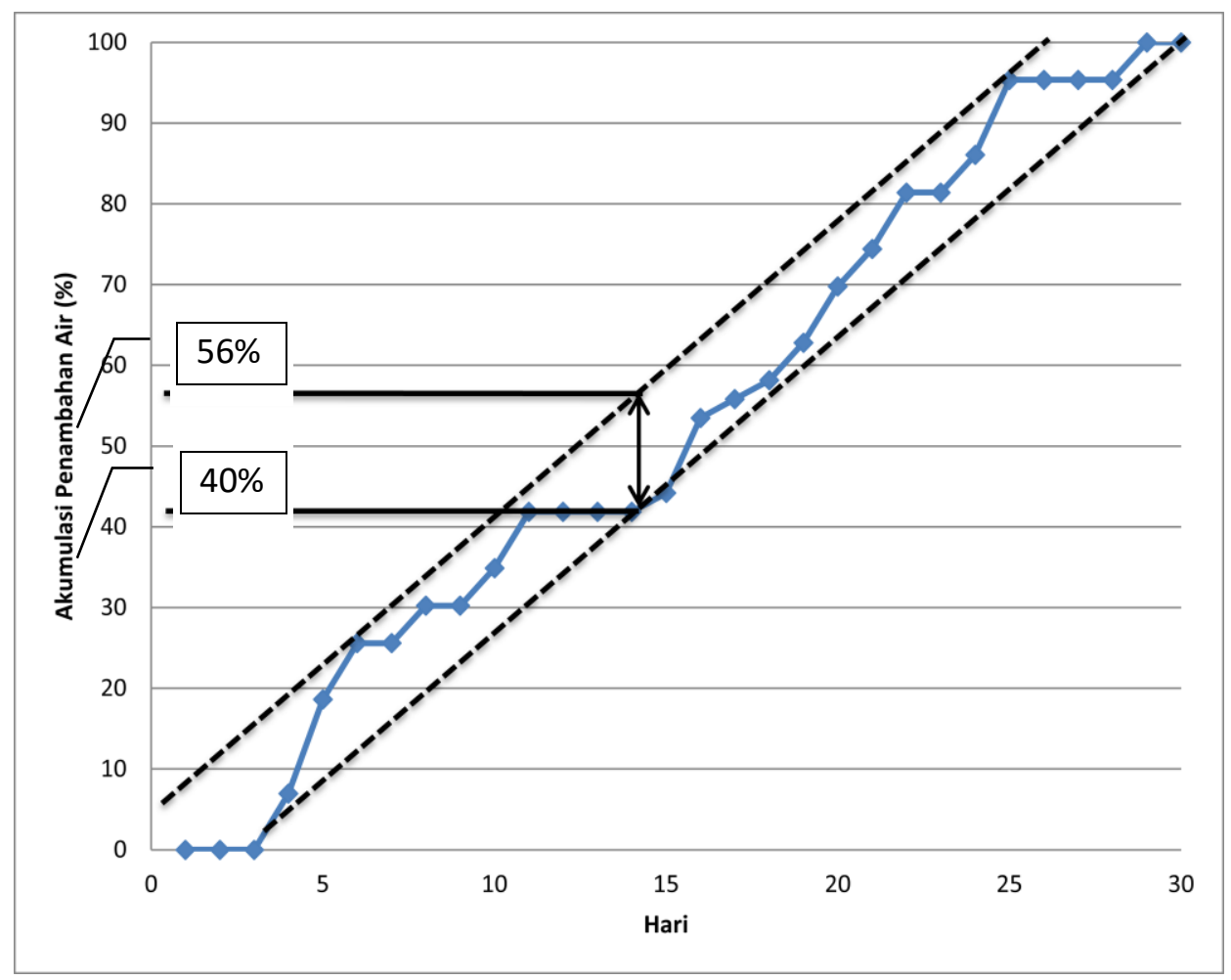

Gambar 2. Persentase Penambahan Air pada Kadar Air Pengomposan $60 \%$

Kalkulasi Gambar 1 dan Gambar 2 diketengahkan sebagai berikut:

1. Persentase Penambahan Air pada Kadar Air Pengomposan 50\%:

a. Penambahan Volume air = Akumulasi Penambahan Volume Air Tertinggi - Akumulasi Penambahan Volume Air Terendah $=67 \%-32 \%=35 \%$. 
b. Penambahan volume air sebesar $35 \%$ setara dengan $500 \mathrm{ml}$ dalam 1,5 $\mathrm{kg}$ massa sampah (5 liter volume sampah) selama 1 siklus pengomposan.

c. Debit input:

Qin $=500 \mathrm{ml} / 30$ hari $=17 \mathrm{ml} / \mathrm{hari}$

d. Ekuivalensi:

1 siklus pengomposan $=1 \mathrm{~kg}$ massa sampah $=334 \mathrm{ml}$ penambahan volume air $=100 \mathrm{~mL}$ penambahan volume air $=24 \%$ penambahan volume air $=17 \mathrm{ml} / \mathrm{hari}$

2. Persentase Penambahan Air pada Kadar Air Pengomposan 60\%:

a. Penambahan Volume air $=$ Akumulasi Penambahan Volume Air Tertinggi - Akumulasi Penambahan Volume Air Terendah $=56 \%-40 \%=16 \%$.

b. Penambahan volume air sebesar $16 \%$ setara dengan $1.075 \mathrm{ml}$ dalam $1,5 \mathrm{~kg}$ massa sampah (5 Liter volume sampah) selama 1 siklus pengomposan.

c. Debit input:

Qin $=1.075 \mathrm{ml} / 30$ hari $=36 \mathrm{ml} / \mathrm{hari}$

d. Ekuivalensi:

1 siklus pengomposan $=1 \mathrm{~kg}$ massa $\mathrm{sampah}=717 \mathrm{ml}$ penambahan volume air $=215 \mathrm{ml}$ penambahan volume air $=16 \%$ penambahan volume air $=36 \mathrm{ml} / \mathrm{hari}$.

Semakin besar kadar air yang diinginkan, maka semakin besar penambahan volume air konstan dan debit input, serta semakin kecilnya persentase penambahan volume air yang mengindikasikan kapasitas tampung reservoir yang semakin kecil.

Dalam perencanaan operasional dapat mengacu pada formulasi ekuivalen dalam 1 siklus pengomposan dan $1 \mathrm{~kg}$ massa sampah atau 1 liter volume sampah.

\section{KESIMPULAN}

Penambahan volume air konstan dengan kadar air yang diinginkan 50\% sebesar $334 \mathrm{ml} / \mathrm{kg}$ sampah/siklus $\approx 100 \mathrm{ml} / 1 \mathrm{sampah} /$ siklus $\approx 24 \%$ penambahan volume air $\approx 17 \mathrm{ml} / \mathrm{hari}$ debit input. Sedangkan penambahan volume air konstan dengan kadar air yang diinginkan $60 \%$ sebesar 717 $\mathrm{ml} / \mathrm{kg} \mathrm{sampah} / \mathrm{siklus} \approx 215 \mathrm{ml} / \mathrm{l} \mathrm{sampah} /$ siklus $\approx 16 \%$ penambahan volume air $\approx 36 \mathrm{ml} /$ hari debit input. 


\section{UCAPAN TERIMA KASIH}

Ucapan terima kasih disampaikan kepada Saudari Dian Asri Puspa Ratna, Sindi Martina Hastuti dan Vaneza Citra Kurnia sebagai mahasiswa Tugas Akhir yang membantu dalam penelitian dan Departemen Teknik Lingkungan FT UNDIP, serta Laboratorium Teknik Lingkungan FT UNDIP.

\section{DAFTAR PUSTAKA}

Bagiawan A., (2013), Perhitungan Kebutuhan Kapasitas Tampung bagi Rencana Pengembangan Areal Layanan irigasi dari Bendung Perjaya-Sumatera Selatan dengan Metode Numerik dan “Sequent Peak", Jurnal Irigasi, Volume 8, Nomor 1.

Chang B.V., Lu Y.S., Yuan S.Y., Tsao T.M., Wang M.K., (2007). Biodegradation of phthalate esters in compost-amended soil, Chemosphere, Volume 74, Issue 6, pp. 873-877.

Dian Asri Puspa Ratna, Ganjar Samudro, Sri Sumiyati, (2017), Pengaruh Kadar Air Terhadap Proses Pengomposan Sampah Organik dengan Metode Takakura, Universitas Mercubuana, DKI Jakarta, Seminar Nasional Pengkajian dan Penerapan Teknologi.

Ministry of Agriculture and Food, (1998), Composting Factsheet - BC Agricultural Composting Handbook (Second Edition 2nd Printing), Canada, BC Ministry of Agriculture, Food and Fisheries.

Samudro,G. and Mangkoedihardjo, S., (2006). Water equivalent method for city phytostructure of Indonesia. Int. J. Environ. Sci. Tech., 3 (3), 261-267.

Sianturi, NM., (2013), Evaluasi Sistem Manajemen Reservoir PDAM tirtauli di Kelurahan Tong Marimbun Kecamatan Siantar Marimbun Kota Pematangsiantar, Jurnal Rancang Sipil Volume 2 Nomor 1.

Sindi Martina Hastuti, Ganjar Samudro, Sri Sumiyati, (2017), Pengaruh Kadar Air terhadap Hasil Pengomposan Sampah Organik dengan Metode Composter Tub, Universitas Mercubuana, DKI Jakarta, Seminar Nasional Pengkajian dan Penerapan Teknologi.

Suehara K.I., Ohta Y., Nakano Y., Yano T., (1999), Rapid Measurement and Control of the Moisture Content of Compost Using Near-Infrared Spectroscopy, Journal of Bioscience and Bioengineering, Volume 87, Issue 6, pp. 769-774. 
Som M.-P., Lemée L., Amblès A., (2009), Stability and maturity of a green waste and biowaste compost assessed on the basis of a molecular study using spectroscopy, thermal analysis, thermodesorption and thermochemolysis, Bioresource Technology, Volume 100, Issue 19, pp. 4404-4416.

Vaneza Citra Kurnia, Ganjar Samudro, Sri Sumiyati, (2017), Pengaruh Kadar Air terhadap Hasil Pengomposan Sampah Organik dengan Metode Open Windrow, Universitas Mercubuana, DKI Jakarta, Seminar Nasional Pengkajian dan Penerapan Teknologi. 